\title{
${ }^{45} \mathrm{CaCl}_{2}$ Autoradiography in Brain from Rabbits with Encephalopathy from Acute Liver Failure or Acute Hyperammonemia
}

\author{
Robert J. de Knegt ${ }^{1}$, Jan-Bert P. Gramsbergen ${ }^{2}$ and Solko W. Schalm ${ }^{1}$.
}

\author{
Received: August 11, 1993; Revised version received: December 16, 1993; \\ Accepted December 21, 1993
}

\begin{abstract}
In experimental hepatic encephalopathy and hyperammonemia, extracellular levels of glutamate are increased in hippocampus and cerebral cortex. It has been suggested that overstimulation of glutamate receptors causes a pathological entry of calcium into neurons via receptor-operated (NMDA- and AMPA-type) or voltage-dependent calcium channels leading to calcium overload and cell death. Neurodegeneration as a result of exposure to excitotoxins, including glutamate, can be localized and quantified using ${ }^{45} \mathrm{CaCl}_{2}$ autoradiography. This approach was used to study cerebral calcium accumulation in rabbits with acute liver failure and acute hyperammonemia. Acute liver failure was induced in 6 rabbits, acute hyperammonemia in 4 rabbits; 4 control rabbits received sodium-potassium-acetate. At the start of the experiment $500 \mu \mathrm{Ci}{ }^{45} \mathrm{CaCl}_{2}$ was given intravenously. After development of severe encephalopathy, the animals were killed by decapitation. All rabbits with acute liver failure or acute hyperammonemia developed severe encephalopathy, after $13.2 \pm 1.7$ and $19.3 \pm 0.5$ hours respectively (mean $\pm S E M$ ). Plasma ammonia levels were $425 \pm 46$ and $883 \pm 21 \mu \mathrm{mol} /$, respectively $(\mathrm{p}<0.05)$. Control rabbits maintained normal plasma ammonia levels $(13 \pm 5 \mu \mathrm{mol} / 1)$, demonstrated normal behaviour throughout the study and were sacrificed after 16 hours. ${ }^{45} \mathrm{Ca}^{2+}$-autoradiograms of $40 \mu \mathrm{m}$ brain sections were analyzed semiquantitatively using relative optical density and computerized image analysis. As compared to background levels ${ }^{45} \mathrm{Ca}$ was not increased in hippocampus or any other brain area of rabbits with severe encephalopathy from acute liver failure or acute hyperammonemia. This suggests that, despite increased extracellular brain glutamate levels in these conditions, glutamate neurotoxicity was not important for the development of encephalopathy in these rabbits.
\end{abstract}

${ }^{1}$ Department of Internal Medicine II, Erasmus University Rotterdam, the Netherlands

2 Department of Neurotoxicology, T.N.O. Medical Biological Laboratory, Rijswijk and Department of Public Health, Erasmus University Rotterdam,the Netherlands

3 To whom correspondence should be addressed at Dept. Internal Medicine II, University Hospital Dijkzigt, Dr. Molewaterplein 40, 3015 GD Rotterdam, The Netherlands 


\section{INTRODUCTION}

Hepatic encephalopathy is a neuropsychiatric syndrome associated with severe liver disease. Hyperammonemia appears to be an important causative factor (1). Ammonia may disturb normal brain function in many ways $(1,2)$, but the precise mechanism of ammonia toxicity in liver disease is unknown.

The amino acid glutamate is the most common excitatory neurotransmitter in the mammalian brain (3) and the metabolism of glutamate is closely related to that of ammonia $(4,5)$. Experimental acute hepatic encephalopathy and acute hyperammonemia appear to be associated with increased extracellular brain concentrations of glutamate (6-9). In addition, increased glutamate concentrations are also found in cerebrospinal fluid of patients with hepatic encephalopathy (10-12). Increased extracellular glutamate levels may cause overstimulation of glutamate receptors. In brain ischemia and epilepsy, there is evidence indicating that prolonged glutamate exposure is deleterious to the brain $(13,14)$. In these conditions most toxic effects are thought to result from a prolonged depolarizing action at postsynaptic ionotropic glutamate receptors $(15,16)$, in particular at the $\alpha$-amino- 3 hydroxy-5-methyl-4-isoxazole propionate (AMPA)-sensitive sites (17). This action is assumed to give rise to membrane permeability changes which lead to impaired ion homeostasis $(15,16)$. In particular, pathological calcium influx via the N-methyl-Daspartate (NMDA) receptor operated cation channel may be responsible for nerve cell swelling and degeneration (18).

The regional distribution of ischemic (19) or excitotoxic (20) brain damage can be visualized and quantified (21) using ${ }^{45} \mathrm{CaCl}_{2}$ autoradiography of brain sections. To determine whether excitotoxic brain injury occurs in hepatic encephalopathy or ammonia toxicity, we performed ${ }^{45} \mathrm{CaCl}_{2}$ autoradiography studies on brains from rabbits with encephalopathy from acute ischemic liver failure and acute hyperammonemia simulating acute liver failure.

\section{METHODS}

\section{Animals}

Twelve New Zealand white rabbits weighing 2-3 kg were used; 6 rabbits with acute liver failure, 4 rabbits with acute hyperammonemia and 4 control rabbits.

\section{Animal models}

Acute liver failure was induced by a two-stage liver devascularisation procedure as described earlier $(22,23)$. Under anesthesia a laparotomy was performed: a loose ligature was placed around the hepatoduodenal ligament and guided through a plastic tube through the abdominal wall to the subcutaneous layer of the left subcostal region, and a small-diameter $(5 \mathrm{~mm})$ side-to-side portacaval shunt was constructed. During this procedure the superior mesenteric artery was clamped to reduce splanchnic blood stasis. To correct acidosis after release of the vascular clamps, $5 \mathrm{ml} 8.4 \%$ sodium bicarbonate were given intravenously. 
Postoperatively the rabbits were given $50 \mathrm{ml} 10 \%$ glucose subcutaneously, followed by standard laboratory chow and water ad libitum. The second day after the operation, acute ischemic liver failure was induced by tightening the loose ligature around the hepatoduodenal ligament after giving $50 \mathrm{mg}$ amoxicillin intravenously. The rabbits were subsequently placed in a restraining box. To prevent hypoglycemia $10 \%$ glucose was given intravenously, starting with a volume of $3 \mathrm{ml} / \mathrm{hr}$ and which was adjusted according to the plasma glucose level when necessary.

Acute hyperammonemia was induced by a prolonged intravenous ammonium acetate $\left(\mathrm{NH}_{4} \mathrm{Ac}\right)$ infusion as described earlier (23). After insertion of a Venflon cannula (diameter $0.8 \mathrm{~mm}$, Viggo, Helsingborg, Sweden) into an ear vein, $\mathrm{NH}_{4} \mathrm{Ac}$ was infused at a constant rate of $6 \mathrm{ml} / \mathrm{hr}$, starting with an initial dose of $0.8 \mathrm{mmol} / \mathrm{kg} / \mathrm{hr}$, which was subsequently increased by $0.2 \mathrm{mmol} / \mathrm{kg} / \mathrm{hr}$ every two hours. After 16 hours the dose remained constant.

Control rabbits received a sodium/potassium acetate (NaKAc) solution, which was infused as in the $\mathrm{NH}_{4} \mathrm{Ac}$ experiments.

\section{Clinical signs of encephalopathy}

During study, all rabbits were kept in a restraining box. However, at regular timeintervals the rabbits were put into a large cage for clinical evaluation. Clinical signs studied were spontaneous activity, body posture, righting reflex, presence of ataxia and reaction to a painful stimulus. In most rabbits with acute hepatic encephalopathy due to ischemic liver cell necrosis two stages of hepatic encephalopathy are easily recognized (24). Stage A is characterized by a disturbed righting reflex: the animal will not get up immediately when placed on its side. At stage $B$, the rabbit lays in the cage and cannot achieve the sitting position, even after stimulation, and usually cannot lift its head. All rabbits with ischemic liver cell necrosis and all rabbits receiving $\mathrm{NH}_{4} \mathrm{Ac}$ were sacrificed by decapitation during encephalopathy stage $\mathrm{B}$. The rabbits receiving NaKAc were sacrificed after 16 hours.

\section{Laboratory measurements}

Arterial blood samples were taken from all rabbits studied, just before the start of the experiment and during severe encephalopathy (stage B). Ammonia was determined with an enzymatic method (25). Blood glucose levels were measured every hour (Haemoglucotest, Boehringer, Germany).

\section{${ }^{45} \mathrm{CaCl}_{2}$ autoradiography}

Autoradiography was performed essentially as described previously (20). Just before the induction of acute liver failure or the start of ammonium acetate or sodium/potassium acetate infusion radioactive calcium chloride $\left(500 \mu \mathrm{Ci}{ }^{45} \mathrm{CaCl}_{2}\right)($ Amersham) in $1 \mathrm{ml}$ of saline) was given intravenously into an ear vein. With development of encephalopathy stage $B$, rabbits with acute liver failure or acute hyperammonemia were sacrificed by decapitation; control rabbits were sacrificed after 16 hours. The brains were rapidly removed from the skull, immediately frozen in isobutanol, which was chilled with dry ice, and stored at $-70^{\circ} \mathrm{C}$ prior to further use. Coronal sections $(40 \mu \mathrm{m})$ through basal ganglia and hippocampus were cut in a cryostat at $-20^{\circ} \mathrm{C}$, and thaw-mounted onto gelatin-chromalum coated glass slides, 
dried on a hot plate $\left(40^{\circ} \mathrm{C}\right)$ and stored at room temperature in the presence of silica gel for 1 day. Subsequently, the dried sections were exposed to $B$-sensitive film (Hyperfilm Bmax, Amersham) in Kodak-X-O-matic cassettes for 7 days and the film was developed in D19 (Kodak).

Autoradiographs were analyzed in a semi-quantitative manner using relative optical density (ROD) and computerized image analysis (MCID software, Imaging Research Inc., Brock University, St. Catherines, Canada). Autoradiographs of ${ }^{45} \mathrm{Ca}$ standards indicated that, relative optical density and radioactivity increase linearly, up to 6 times background level (=ROD in control brain tissue), and that a ROD increase of $\partial \%$ (versus background) represents a relative radioactivity increase $\left(={ }^{45} \mathrm{Ca}\right.$ increase $)$ of $2 \partial \%$. The ratio of ROD dorsal hippocampus versus ROD background (in the rest of the same brain section) was calculated for both hemispheres in 12 consecutive sections (distance between sections $120 \mu \mathrm{m}$ ), to obtain the relative increase in ROD in the dorsal hippocampus of each animal. Using this approach a ratio of $<1$ denotes decreased labelling, $>1$ increased labelling and 1 unchanged labelling as compared to the rest of the brain.

After exposure to autoradiographic film, brain sections were stained with thionine according to standard procedures

\section{Necropsy}

After sacrifice of the animals, necropsy was performed to exclude gross pathological abnormalities. In the animals with acute ischemic liver cell necrosis the liver was examined carefully to confirm tightening of the ligature.

\section{Statistics}

The results are presented as mean \pm S.E.M. For statistical analysis unpaired Student's $t$ test was used. Statistical significance denotes $p<0.05$.

All experiments were approved by the Ethical Committee on Animal Research of the Erasmus University Rotterdam.

\section{RESULTS}

\section{Clinical signs of encephalopathy}

Encephalopathy from acute liver failure was characterized by complete loss of spontaneous activity, impaired body posture, absence of the righting reflex and decreased muscle tone. One rabbit with acute liver failure developed ataxia. Rabbits with encephalopathy from acute hyperammonemia exhibited similar symptoms, but in addition, all four rabbits developed ataxia. One rabbit with hyperammonemia developed generalized seizures and died spontaneously immediately thereafter. All animals with acute liver failure or acute hyperammonemia developed encephalopathy stage $B$, after $13.2 \pm 1.7(n=6)$ and $19.3 \pm 0.5(n=4)$ hours respectively ( $p>0.05)$. Control studies were performed for 16 hours; all four control rabbits exhibited normal behaviour until the end of the experiments. 


\section{Plasma ammonia and glucose levels}

At the start of the experiments ammonia levels tended to be higher in rabbits with acute liver failure $(86 \pm 22 \mu \mathrm{mol} / 1)$, due to their portacaval shunt, when compared to rabbits with acute hyperammonemia $(19 \pm 13 \mu \mathrm{mol} / 1)$ or controls $(25 \pm 9 \mu \mathrm{mol} / \mathrm{l})$. However, the difference did not reach statistical significance $(p>0.05)$. During encephalopathy stage $B$ the difference in plasma ammonia levels between rabbits with acute liver failure $(425 \pm 46 \mu \mathrm{mol} / 1)$ and rabbits with acute hyperammonemia $(883 \pm 21)$ reached statistical significance $(p<0.05)$. At the end of the control experiments ammonia levels had not changed $(13 \pm 5 \mu \mathrm{mol} / 1)$.

Hypoglycemia was not observed. In control rabbits plasma glucose levels were $8.4 \pm 0.5$ $\mathrm{mmol} / \mathrm{l}$ at the start, and $7.6 \pm 0.1 \mathrm{mmol} / \mathrm{l}(\mathrm{p}>0.05)$ at the end of the experiments. In rabbits with acute liver failure these levels were $7.9 \pm 0.1 \mathrm{mmol} / 1$ and $8.2 \pm 0.6$ respectively ( $>0.05$ ); and in rabbits with acute hyperammonemia $9.0 \pm 0.4 \mathrm{mmol} / 1$ and $16.4 \pm 2.8$ $\mathrm{mmol} / \mathrm{l}$ respectively $(\mathrm{p}<0.05)$.

\section{${ }^{45}$ Ca-autoradiography}

Autoradiographs from control brains showed a diffuse greyish labelling, and no regional distribution of the label. Autoradiographs from rabbits with acute liver failure and acute hyperammonemia also showed a diffuse greyish labelling. In two rabbits with acute liver failure and in one rabbit with acute hyperammonemia a slight increased labelling of the hippocampal region was observed (figure 1a).

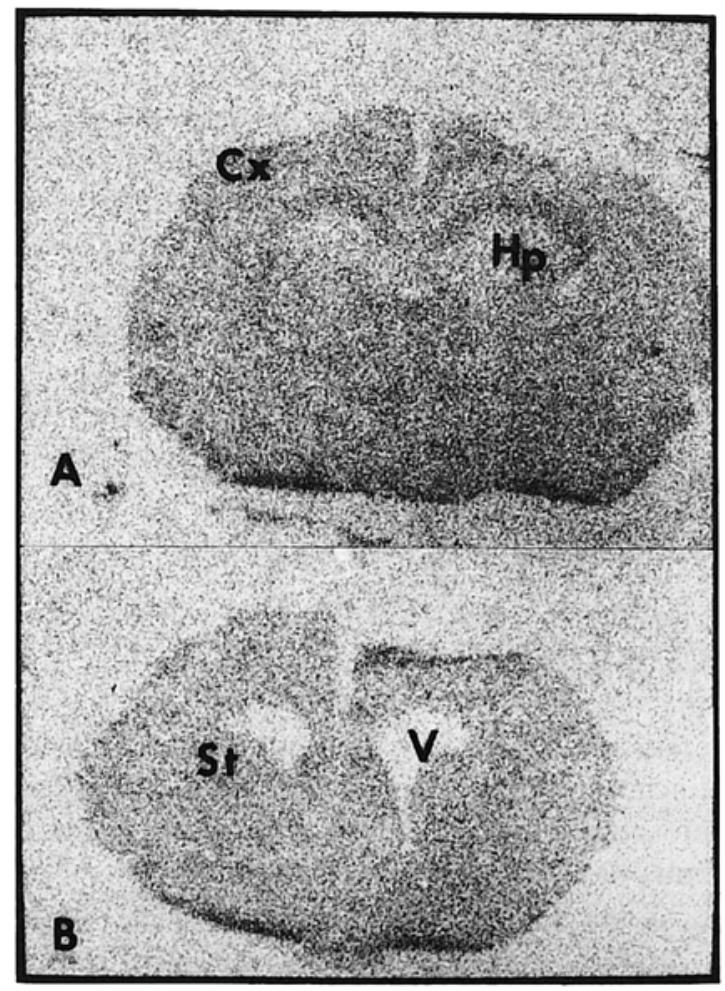

Figure 1. Representative ${ }^{45} \mathrm{Ca}_{2}$-autoradiographs of coronal brain slices $(40 \mu \mathrm{m})$, from a rabbit with acute liver failure.

A: Hippocampus

B: Striatum. Magnification $3 x$.

CX: Cortex; Hp: Hippocampus;

St: Striatum; V: Ventricle. 
However, quantification of the ratio of ROD hippocampus versus ROD background (=ROD surrounding brain tissue in the same section), revealed no significant differences between rabbits with acute liver failure, acute hyperammonemia and controls (table 1). In addition, the histology of the hippocampal pyramidal cell layer in the sections used for autoradiography, appeared to be normal in both rabbits with acute liver failure or acute hyperammonemia (data not shown). Finally, also in striatum, or any other brain area in the forebrain of rabbits with acute liver failure or acute hyperammonemia, no ${ }^{45} \mathrm{Ca}$ accumulation was found (figure $1 \mathrm{~b}$ ).

Table 1. Ratios of relative optical densities of dorsal hippocampus versus background in brains from rabbits with acute liver failure, acute hyperammonemia and controls.

\begin{tabular}{llll}
\hline Experimental group & Hippocampus, & $\begin{array}{c}\text { Hippocampus, } \\
\text { left }\end{array}$ & $\begin{array}{c}\text { right } \\
\text { Acute liver failure }\end{array}$ \\
& 1 & $1.011 \pm 0.014$ & $1.002 \pm 0.014$ \\
& 3 & $0.997 \pm 0.017$ & $0.999 \pm 0.016$ \\
& 4 & $1.024 \pm 0.011$ & $1.017 \pm 0.009$ \\
& 5 & $1.021 \pm 0.015$ & $0.965 \pm 0.009$ \\
& 6 & $0.943 \pm 0.010$ & $0.907 \pm 0.014$ \\
& mean \pm SEM & $1.000 \pm 0.012$ & $0.978 \pm 0.016$ \\
\hline Hyperammonemia & 1 & $0.961 \pm 0.014$ & $0.909 \pm 0.007$ \\
& 2 & $0.925 \pm 0.011$ & $0.918 \pm 0.011$ \\
& 3 & $0.979 \pm 0.012$ & $0.971 \pm 0.016$ \\
& 4 & $0.978 \pm 0.011$ & $0.950 \pm 0.010$ \\
\hline Control & mean $\pm S E M$ & $0.961 \pm 0.013$ & $0.937 \pm 0.014$ \\
& 1 & $0.979 \pm 0.011$ & $0.954 \pm 0.010$ \\
& 2 & $0.937 \pm 0.006$ & $0.930 \pm 0.010$ \\
& 3 & $1.020 \pm 0.006$ & $0.993 \pm 0.007$ \\
& 4 & $1.021 \pm 0.011$ & $1.009 \pm 0.015$ \\
\hline & mean $\pm S E M$ & $0.989 \pm 0.020$ & $0.972 \pm 0.018$ \\
\hline
\end{tabular}

Ratios in individual rabbits represent the mean \pm SEM of 12 consecutive brain sections.

\section{DISCUSSION}

The present results show that there is no regional ${ }^{45} \mathrm{Ca}^{2+}$ accumulation in the brains of rabbits with severe encephalopathy from acute liver failure or acute hyperammonemia. Thus, despite findings of increased cerebrospinal fluid and extracellular brain levels of glutamate (6-9,32), as well as increased brain tissue and cerebrospinal fluid levels of the excitotoxin quinolinic acid in both clinical and experimental hepatic encephalopathy 
$(26,27)$, we could not demonstrate excitotoxic brain damage in experimental acute hepatic encephalopathy using ${ }^{45} \mathrm{CaCl}_{2}$ autoradiography. The latter technique has been shown to be a sensitive tool to demonstrate cerebral calcium accumulation, in pathological conditions associated with excitotoxicity $(19-21,28)$. Furthermore, increases of extracellular brain glutamate, during cerebral ischemia (3.5-8 fold)(29) and hypoglycemia (2.5 fold)(30), conditions considered to be associated with glutamate-related neurototoxicity, are similar to those found during acute liver failure (6-8). In addition, hippocampus and striatum were chosen because these brain regions are known to contain a large number of glutamate receptors (33). And although we cannot exclude overall changes based on measurements relative within each brain, most prominent changes would have been expected to occur in hippocampus and/or striatum. However, increased glutamate levels in brain dialysates produced by ischemia are derived from the metabolic pool rather than the transmitter pool (31). Furthermore, several attempts to detect changes in glutamate release using microdialysis after electrical or chemical stimulation of glutamatergic fibers have failed (31). Therefore, it has been questioned whether changes of glutamate in the excitatory synapse can be monitored by microdialysis. Thus, the reported increased glutamate levels in brain dialysates following experimental acute liver failure, may also be of metabolic origin and may not be able to reach excitatory synapses, where AMPA or NMDA receptors are localized.

Another explanation for our negative results, may be the relative short duration of the pathological condition. After ischemic or excitotoxic brain injury, calcium accumulation and cell death increase up to at least seven days after the initial insult (21). We have studied our animals 12-20 hours after the induction of acute liver failure or acute hyperammonemia, i.e. the duration of significantly increased extracellular glutamate was even less (6). Thus, in our experimental models there might not have been enough time to develop excitotoxic brain damage. This possible explanation, of course, should be tested in more chronic models of hepatic encephalopathy.

\section{ACKNOWLEDGEMENTS}

We thank Ms. Alita van der Sluijs-Gelling (TNO Medical Biological Laboratory, Rijswijk, the Netherlands) for expert technical assistance with the ${ }^{45} \mathrm{Ca}$ autoradiography.

\section{REFERENCES}

1. Butterworth R.F. (1991) Pathophysiology of hepatic encephalopathy; the ammonia hypothesis revisited. In: Bengtsson F, Jeppsson B, Almdal T, Vilstrup $\mathrm{H}$, Eds. Progress in Hepatic Encephalopathy and Metabolic Nitrogen Exchange. CRC Press, pp 9-24.

2. Raabe W. (1987). Synaptic transmission in ammonia intoxication. Neurochem. Pathol. 6:145-166.

3. Fonnum F. (1984). Glutamate: a neurotransmitter in mammalian brain. $J$. Neurochem. 42:1-11.

4. Cooper A.J.L., Plum F. (1987). Biochemistry and physiology of brain ammonia. Physiol. Rev. 67:440-519.

5. Kaneko T., Shigemoto R, Mizuno N. (1988). Metabolism of glutamate and ammonia in astrocyte: an immunocytochemical study. Brain. Res. 457:160-164.

6. De Knegi R.J., Schalm S.W., Van der Rijt C.C.D., Fekkes D., Dalm E., Hekking-Weijma I. (1994). Extracellular brain glutamate during acute liver failure and during acute hyperammonemia simulating acute liver failure. An experimental study based on in-vivo brain dialysis. J. Hepatol. 20:19-26. 
7. Hamberger A., Nystrom B. (1984). Extra- and intracellular amino acids in the hippocampus during development of hepatic encephalopathy. Neurochem. Res. 9:1181-1192.

8. Bosman D.K., Deutz N.E.P., Maas M.A.W., Van Eijk H.M.H., Smit J.J.H., De Haan J.G. et al. (1992), Amino acid release from cerebral cortex in experimental acute liver failure studied by in vivo cerebral cortex microdialysis. J. Neurochem. 59:591-599.

9. Moroni F, Lombardi G., Moneti G., Cortesini C. (1983). The release and neosynthesis of glutamic acid are increased in experimental models of hepatic encephalopathy. J. Neurochem. 40:850-854.

10. Van Sande M., Mardens Y., Adriaen.ssens K., Löwenthal A. (1970). The free amino acids in human cerebrospinal fluid. J. Neurochem. 17:125-135.

11. Watanabe A., Takei N., Higashi T. (1984). Glutamic acid and glutamine levels in serum and cerebrospinal fluid in hepatic encephalopathy. Biochem. Med. 32:225-231.

12. Vergara F., Plum F., Duffy T.E. (1974), $\alpha$-Ketoglutarate: increased concentrations in the cerebrospinal fluid of patients with hepatic coma. Science 183:81-83.

13. Engelsen B. (1986). Neurotransmitter glutamate: its clinical importance. Acta Neurol. Scand. 74:337355 .

14. Choi D.W. (1988). Glutamate neurotoxicity and diseases of the brain. Neuron 1:623-634.

15. Rothman S.M., Olney J.W. (1986). Glutamate and the pathophysiology of hypoxic-ischemic brain damage. Ann. Neurol. 19:105-111.

16. Rothman S.M., Olney J.W. (1987). Excitotoxicity and the NMDA receptor. TINS 10:299-302.

17. Fagg G.E., Massieu L. (1991). Excitatory amino acid receptor subtypes. In: Meldrum BS, Ed. Excitatory Amino Acid Antagonists. Blackwell Scientific Publications London, pp 39-63.

18. Collias R.C., Dobkin B.H., Choi D.W. (1989). Selective vulnerability of the brain: new insights into the pathophysiology of stroke. Ann. Intern. Med. 110:992-1000.

19. Dienel G.A. (1984).. Regional accumulation of calcium in postischemic rat brain. J. Neurochem. 43:913-925.

20. Gramsbergen J.B.P., Veenma-Van der Duin L., Loopuijt L., Paans A.M.J., Vaalburg W., Korf J. (1988). Imaging of the degeneration of neurons and their processes in rat or cat brain by ${ }^{45} \mathrm{CaCl}_{2}$ autoradiography or ${ }^{55} \mathrm{CoCl}_{2}$ positron emission tomography. J. Neurochem. 50:1798-1807.

21. Gramsbergen J.B.P., Van der Sluijs-Gelling A. (1993). Time and dose dependent ${ }^{45} \mathrm{Ca}^{2+}$ accumulation in rat striatum and substantia nigra after an intrastriatal injection of quinolinic acid. Exp. Neurol. 121:261-269.

22. Fick T.E., Schalm S.W., De Vlieger M. (1987). A surgical model of fulminant hepatic failure in the rabbit: different effects of end-to-side versus small-diameter side-10-side portacaval shunt. Eur. Surg. Res. 19:276-282.

23. Fick T.E., Schalm S.W., De Vlieger M. (1989). Continuous intravenous ammonia infusion as a model for the study of hepatic encephalopathy in rabbits. J. Surg. Res. 46:221-225.

24. Van der Rijt C.C.D., De Knegt R.J., Schalm S.W., Terpstra O.T., Mechelse K. (1990). Flumazenil does not improve bepatic encephalopathy associated with acute ischemic liver failure in the rabbit. Metab. Brain Dis. 5:131-141.

25. Da Fonseca.Wolheim F. (1973), Direkte plasma ammonia Bestimmung ohne Enteiweissung. Z. Klin. Chem. Klin. Biochem. 11:426 431.

26. Moroni F., Lombardi G., Carla V., Lal S., Etienne P., Nair N.P.V. (1986). Increase in the content of quinolinic acid in cerebrospinal fluid and frontal cortex of patients with hepatic failure. $J$. Neurochem. 47:1667-1670.

27. Moroni F., Lombardi G., Carla V., Pellegrini D., Carassale G.L., Cortesini C. (1986). Content of quinolinic acid and other tryptophan metabolites increases in brain regions of rats used as experimental models of hepatic encephalopathy. J. Neurochem. 46:869-873.

28. Kato H., Kogure K, Nakano S. (1989). Neuronal damage following repeated brief ischemia in the gerbil. Brain Res. 479:366-370.

29. Benveniste H., Drejer J., Schousboe A., Diemer N.H. (1984). Elevation of the extracellular concentrations of glutamate and aspartate in rat hippocampus during transient cerebral ischemia monitored by intracerebral microdialysis. J. Neurochem. 43:1369-1374.

30. Buicher S.P., Sandberg M., Hagberg H., Hamberger A. (1987). Cellular origins of endogenous amino acids released into the extracellular fluid of the rat striatum during severe insulin-induced hypoglycemia. J. Neurochem. 48:722-728.

31. Christensen T., Bruhn T., Diemer N.H., Schousboe A. (1991). Effect of phenylsuccinate on potassiumand ischemia-induced release of glutamate in rat hippocampus monitored by microdialysis. Neurosci. Lett. 134:71-74.

32. Swain M.S., Bergeron M., Audet R., Blei A.T., Butterworth R.F. (1992). Monitoring of neurotransmitter amino acids by means of an indwelling cisterna magna catheter: a comparison of two rodent models of fulminant hepatic failure. Hepatology 16:1028-1035.

33. Ottersen O.P.. (1991). Excitatory amino acid neurotransmitters: anatomical systems. In: Meldrum BS, Ed. Excitatory Amino Acid Antagonists. Blackwell Scientific Publications, pp 14-38. 